\title{
PENGARUH E-SPORTS MARKETING DAN KEPUASAN PELANGGAN TERHADAP BRAND LOYALTY RAZER INC.
}

\section{Ferdy Gunardi}

Universitas Matana, Tangerang

Email: ferdy.gunardi@matanauniversity.ac.id

\begin{abstract}
Abstrak
Penelitian ini bertujuan untuk mengetahui pengaruh dari penggunaan e-sports sebagai alat pemasaran serta kepuasan pelanggan yang sebagai variabel terhadap brand loyalty kepada merek Razer Inc. Pada masa dimana bermain video games bukanlah sesuatu yang dinilai sebagai suatu kegiatan yang nihil atau sia - sia industri video games semakin berkembang dengan munculnya sisi kompetitif secara profesional yang disebut sebagai e-sports. Munculnya berbagai macam kesempatan di dalam industri besar ini mendorong berbagai perusahaan yang berkaitan dengan video games berdiri dan berkembang, tidak hanya perusahaan baru namun banyak perusahaan besar lainnya melakukan berbagai macam investasi di dalam ranah e-sports. Dalam penelitian ini yang menjadi objek penelitian adalah perusahaan gaming gear yaitu Razer Inc. Variabel independen dalam penelitian ini adalah e-sports marketing dan kepuasan pelanggan $(x)$ dan variabel dependen dalam penelitian ini adalah brand loyalty (y). Berdasarkan penelitian yang didapatkan, ditemukan bahwa adanya pengaruh yang cukup signifikan pada variabel e-sports marketing dan kepuasan pelanggan terhadap brand loyalty dari merek Razer. Sisi yang perlu lebih dikembangkan adalah perluasan pengetahuan mengenai program Razer yang mendukung pemain profesional.
\end{abstract}

Kata kunci: E-sports; E-sports Marketing; Kepuasan Pelanggan; Brand Loyalty

\section{Pendahuluan}

Informasi menjadi sebuah kebutuhan yang pokok, agar dapat terus memperbaharui biasanya mencari dan mendapatkannya melalui media cetak, elektronik dan internet. Seperti halnya makhluk hidup yang membutuhkan makan, maka informasi juga sudah menjadi kewajiban untuk segera dipenuhi, jika tidak terpenuhi maka bisa berpengaruh buruk bagi penggunanya (Pramadita, 2017). Industri e-sports semakin berkembang di dunia dan memiliki jumlah audience yang tidak kalah dengan liga olahraga fisik seperti NBA dan Super Bowl. Menurut (Hamari \& Sjöblom, 2017) esports adalah sebuah bentuk olahraga yang dimana aspek utamanya difasilitasi oleh sistem elektronik; input pemain dan tim serta output dari sistem e-sports dimediasi oleh interaksi antarmuka antara manusia dan komputer.

Selama beberapa tahun terakhir, e-sports (electronic sports) telah menjadi salah satu bentuk media baru yang berkembang sangat pesat yang didorong oleh berkembangnya game (online) dan teknologi penyiaran online. Diperkirakan lebih dari 
70 juta orang menonton e-sports sepanjang tahun 2013. Industri ini telah mengalami pertumbuhan sangat pesat dimana berdasarkan data yang dikutip dari hybrid.co.id pendapatan dari industri game untuk kawasan GSEA (Greater Southeast Asia) yang mencakup berbagai negara seperti taiwan beserta negara - negara asia tenggara lainnya diperkirakan akan mengalami pengingkatan dari Rp 70,4 triliun pada tahun 2019 menjadi Rp 116,8 triliun pada tahun 2023. Salah satu faktor yang mempengaruhi pertumbuhan ini adalah jumlah gamer baik mobile maupun pc. Jumlah gamer pc diperkirakan akan bertumbuh menjadi 186,3 juta orang pada tahun 2023, dan itu hanya dikawasan GSEA. Jumlah gamers yang aktif ikut berpartisipasi dalam e-sport di GSEA berjumlah 95\% dari total gamers. Dengan jumlah audience yang begitu besar, banyak perusahaan besar yang mulai melirik industri ini sebagai celah investasi, bisnis dan pemasaran baru yang akan terus berkembang dalam jangka waktu yang lama (venturebeat.com, 2019). Secara global industri e-sport sendiri pada tahun 2017 sudah meghasilkan $\$ 696 \mathrm{M}$ yang mencakup $\$ 115 \mathrm{M}$ dari game publisher fees, $\$ 95.2 \mathrm{M}$ dari mediar rights, $\$ 15.3 \mathrm{M}$ dari advertising, $\$ 226.3 \mathrm{M}$ dari sponsorship, dan $\$ 63.7 \mathrm{M}$ dari merchandise \& tickets. Bila dilihat perbandingannya dengan apa yang dihasilkan oleh industri ini di GSEA seperti yang telah dibahas diatas maka dapat dilihat betapa pesatnya perkembangan dari industri ini, namun sayangnya banyak orang yang mengesampingkannya.

Berdasarkan data yang diambil dari invenglobal.com yang disediakan oleh Nielsen Holdings yang telah bekerjasaam dengan Riot (perusahaan pengembang dari game League of Legends) dalam hal pengumpulan data menyatakan bahwa jumlah audience untuk World Championship League of Legends 2019 yang merupakan sebuah game bergenre MOBA (Multiplayer Online Battle Arena) dengan Audience terbesar berjumlah 21.8 juta AMA (Average Minute Audience) yang berarti jumlah individual atau kelompok yang menonton turnamen tersebut secara online dalam periode waktu terentu selama durasi program. Dengan puncak penonton berjumlah 44 juta AMA. Jumlah AMA dari turnamen e-sport sudah melampaui jumlah penonton AMA dari liga olahraga fisik seperti NBA yang meiliki puncak penonton AMA tertinggi berjumlah 20.4 juta penonton pada tahun 2017 dan menurun menjadi 15.14 juta pada tahun 2019 (Statista.com). Dari data yang diambil dari penji.co, perusahaan besar seperti Red Bull, Intel, Taco Bell, ESPN sudah memasuki industri ini. Red Bull sudah melakukan banyak sponsorship dengan berbagai tim e-sport profesional dan juga streamer seperti Richard Tyler Blevins atau yang lebih dikenal dengan sebutan Ninja yang merupakan salah satu streamer dengan audience terbesar. Intel melakukan sponsorship dengan memberikan komputer yang dilengkapi dengan teknologi mereka. ESPN yang merupakan media olahraga terbesar membuat ESPN khusus untuk kategori gaming.

Dilansir dari AdAge.com, e-sports marketing telah menjadi kewajiban bagi seluruh marketer terutama bagi seorang CMO (Chief Marketing Officer). Menurut Tobias Sherman, kepala global e-sports dari salah satu Media \& Talent Agency ternama di Amerika yaitu Endeavor Group Holdings, "If you are a CMO and you are not in esports in 2017, you are going to risk getting fired,". Kalimat ini menunjukan betapa 
pentingnya e-sports marketing bagi suatu brand sekarang ini. Ekonomi esports global yang mencakup hak media, iklan, sponsor, penjualan merchandising, dan penjualan tiket akan tumbuh sebesar $41 \%$ pada 2017 menjadi \$ 696 juta dan mencapai \$ 1,49 miliar pada 2020, menurut Newzoo, yang menyediakan intelijen pasar untuk esports dan permainan global.

Dalam industri gaming/e-sport yang semakin berkembang para gamers memiliki tuntutan dalam kenyamanan dalam bermain dan membutuhkan peralatan pelengkap yang dapat memenuhi kebutuhan tersebut. Dikutip dari theguardian.com, kebutuhan tersebut salah satunya berupa headset yang dapat membantu mendengar langkah musuh dan arah suara serta fitur komunikasi yang baik sehingga dapat berkomunikasi dengan jelas dengan teman satu tim. Kebutuhan yang kedua adalah monitor yang baik sehingga dapat melihat target dan area sekitar pemain terlihat dengan jelas tanpa masalah dikarenakan monitor dengan screen input lag yang kecil dapat memberikan milidetik yang vital dalam melakukan gerakan. Dalam bermain game akurasi dan koordinasi tangan sangatlah penting karenanya dibutuhkan mouse dengan kanyamanan dan waktu respon yang baik sehingga pergerakan sesuai dengan kemauan pemain sehingga bentuk mouse dan tombol utama yang dapat di klik dengan cepat menjadi kriteria utama dalam memilih mouse. Peralatan terakhir yang tidak kalah penting adalah keyboard, para ahli merekomendasikan mechanical keyboard sebagai pilihan utama dikarenakan memiliki respon yang cepat dan memiliki ketahanan yang sangat baik sehingga dapat memasukan input dengan cepat dan presisi. Dari kebutuhan tersebut munculah berbagai macam gaming gear dengan kostumisasi yang berbeda-beda disesuaikan dengan kebutuhan.

Adapun sebuah perusahaan yang memproduksi gaming gear pertama dan telah menjadi salah satu pemimpin dalam industrinya adalah Razer Inc. Perusahaan ini berdiri pada tahun 2005 oleh Min-Liang Tan and Robert Krakoff dan berhasil menjadi salah satu brand premium. Menurut CNBC.com, Razer Inc. Memiliki nilai sebesar \$2.2 Billion pada tahun 2018 dan naik menjadi \$9.8 Billion di tahun 2020 dimana Razer Inc. Lebih unggul dibandingkan dengan kompetitornya seperti Logitech yang memiliki nilai sebesar \$8.11B dan Turtle Beach yang bernilai sebesar \$146.16M.

Pada penelitian ini penulis ingin mengetahui pengaruh dari e-sports marketing dan faktor - faktor lainnya yang mempengaruhi brand loyalty terhadap produk - produk yang diproduksi oleh Razer Inc.

Pemasaran menurut (Andayani, 2014) adalah suatu proses di mana di dalamnya, seorang individu dan/atau sebuah kelompok mendapatkan apa yang mereka butuhkan dan inginkan dengan menciptakan, menawarkan, dan secara bebas mempertukarkan produk yang bernilai dengan pihak lain.

Menurut (Kotler, n.d.), definisi dari pemasaran adalah sebagai berikut: "Marketing is about identifying and meeting human and social needs. One of the shortest good definitions of marketing is meeting needs profitably".

Menurut The American Marketing Association (AMA) yang telah dikutip oleh (Kotler, n.d.) pemasaran adalah sebuah aktivitas, institusi dan proses untuk 
menciptakan, mengkomunikasikan, mengirimkan dan bertukar penawaran yang memiliki nilai bagi kostumer, klien, partner dan masyarakat secara umum.

Menurut (Ari Setyaningrum, 2015), pemasaran merupakan sebuah subjek yang sangat penting dan dinamis, karena pemasaran menyangkut kegiatan sehari-hari dalam sebuah masyarakat.

Dari teori-teori tersebut dapat disimpulkan bahwa pemasaran merupakan sebuah kegiatan yang melakukan penawaran, komunikasi dan pertukaran sesuatu yang memiliki nilai dan menghasilkan keuntungan dari kebutuhan masyarakat.

Menurut (Fletcher, 2015), yang merupakan pendiri dari Entiva Group, LLC, yang mengembangkan individual bertalenta dan solusi inovatif dalam industri e-sports, yang dilansir dari esportobserver.com bahwa e-sports marketing sampai saat ini masih belum ada pendekatan yang komperhensif mengenai definisinya secara pasti. Namun secara umum e-sports marketing dapat didefinisikan sebagai sebuah spektrum dari suatu aktivitas pemasaran yang didesain untuk memenuhi kebutuhan dan keinginan dari konsumernya. Dimana konsumer dan konsumsinya mencakup bermain, bertaruh, menonton, membaca dan membuat konten yang berasosiasikan dengan e-sports.

Didalamnya sendiri terdapat dua jenis e-sports marketing, yang pertama adalah pemasaran dari acara atau jasa e-sports dan yang kedua adalah e-sports sebagai marketing vehicle. Sebagai contoh: ESL (Electronic Sports League) yang melakukan pemasaran jenis pertama serta HTC yang melakukan sponsorship kepada tim profesional Cloud9 sebagai jenis yang kedua (Fletcher, 2015).

Maka dari penjelasan di atas dapat disimpulkan bahwa e-sports marketing adalah sebuah kegiatan pemasaran suatu produk atau merek melalui media e-sports.

Menurut Kotler dan Keller dalam (Priansa, 2017), kepuasan konsumen adalah perasaan senang atau kecewa seseorang yang muncul setelah membandingkan antara kinerja (hasil) produk yang diperkirakan terhadap kinerja atau hasil yang diharapkan. Jika kinerja di bawah harapan berarti konsumen tidak puas. Jika kinerja memenuhi harapan berarti konsumen puas. Jika kinerja melebihi harapan maka konsumen sangat puas atau senang.

Menurut (Kotler, n.d.) kepuasan pelanggan adalah perasaan kesenangan atau kekecewaan seseorang yang dihasilkan dari membandingkan kualitas performa produk atau hasil dengan ekspektasi seseorang.

Menurut Tse dan Wilton dalam (Saputro, Hufron, \& Slamet, 2017) kepuasan adalah sebuah respons pelanggan setelah pemakaian yang didasari oleh ketidaksesuaian antara harapan sebelumnya dengan performa sesungguhnya dari suatu produk.

Dari penjelasan di atas maka penulis dapat menyimpulkan bahwa kepuasan pelanggan adalah sebuah reaksi perasaan baik itu senang maupun kecewa yang dirasakan oleh konsumen dikarenakan adanya perbandingan dan ketidaksesuaian antara ekspektasi dan performa sesungguhnya dari suatu produk.

Menurut (Kotler, n.d.) loyalitas merek adalah komitmen yang dipegang secara mendalam untuk membeli atau mendukung kembali produk atau jasa yang disukai di 
masa depan meskipun adanya pengaruh situasi dan usaha pemasaran yang berpotensi menyebabkan konsumen beralih kepada produk lain.

Menurut (Schiffman, L., Wisenblit, L., 2015), loyalitas merek adalah pembelajaran konsumen mengenai pembelian sebuah merek tanpa melihat alternatif lain yang tersedia. Loyalitas merek merupakan inti yang menjadi gagasan dalam kegiatan pemasaran, dikarenakan hal ini merupakan suatu ukuran keterkaitan seorang pelanggan kepada sebuah merek.

Loyalitas Menurut (Tjiptono, 2014) adalah perilaku pembelian ulang yang menyangkut pembelian merek tertentu yang sama secara berulang-ulang (bisa dikarenakan memang hanya satu satunya merek yang tersedia, merek termurah dan sebagainya).

Dapat disimpulkan oleh penulis bahwa loyalitas merek adalah sebuah komitmen dan proses pembelajaran konsumen mengenai merek tertentu dan adanya pembelian berulang serta dukungan terhadap merek tertentu.

\section{Metode Penelitian}

Metode penelitian yang digunakan adalah metode kualitatif. Sumber data kualitatif dalam penelitian ini berasal dari sumber sekunder yang diperoleh melalui studi Pustaka, Teknik pengumpulan data dalam penulisan ini adalah melalui literature review dengan objek penelitian Razer Inc.

\section{Hasil dan Pembahasan}

Berdasarkan hasil penelitian oleh (H.B, 2016) e-sports mempengaruhi pertumbuhan brand loyalty dikarenakan konsumen sangat mengapresiasi adanya keikutsertaan merek tersebut dalam passion mereka, dikarenakan dunia gaming secara luas sebelumnya dianggap sebagai ranah yang tidak pantas atau hanya sebagai permainan yang tidak menghasilkan.

Menurut (Gawrysiak, Burton, Jenny, \& Williams, 2020) e-sports dapat secara efisien meningkatkan persepsi konsumen terhadap suatu merek yang berpengaruh terhadap loyalitas konsumen terhadap merek tersebut.

Berdasarkan data yang didapat dari hasil penelitian dengan menggunakan kuesioner kepada 30 orang responden yang dilakukan oleh penulis dapat dilihat bahwa e-sports marketing dan kepuasan pelanggan cukup berpengaruh terhadap loyalitas konsumen akan suatu merek.

A. Penelitian ini memiliki hipotesis berikut:

H1. Diduga bahwa adanya pengaruh dari e-sports marketing terhadap loyalitas merek Razer Inc.

H2. Diduga bahwa adanya pengaruh dari kepuasan pelanggan terhadap loyalitas merek Razer Inc.

H3. Diduga bahwa adanya pengaruh dari e-sports marketing dan kepuasan pelanggan terhadap loyalitas merek Razer Inc. 
B. Hasil dari penelitian ini adalah sebagai berikut:

1. E-sports marketing berpengaruh cukup signifikan terhadap loyalitas merek Razer Inc.

2. Kepuasan pelanggan berpengaruh signifikan terhadap loyalitas merek Razer Inc.

3. Pemakaian merek Razer Inc oleh pemain profesional dan streamer serta sponsorship terhadap pemain atau tim profesional mempengaruhi loyalitas merek Razer Inc disertai kepuasan pelanggan terhadap produknya.

\section{Kesimpulan}

Berdasarkan hasil penelitian oleh (H.B, 2016) e-sports mempengaruhi pertumbuhan brand loyalty dikarenakan konsumen sangat mengapresiasi adanya keikutsertaan merek tersebut dalam passion mereka, dikarenakan dunia gaming secara luas sebelumnya dianggap sebagai ranah yang tidak pantas atau hanya sebagai permainan yang tidak menghasilkan.

Menurut (Gawrysiak et al., 2020) e-sports dapat secara efisien meningkatkan persepsi konsumen terhadap suatu merek yang berpengaruh terhadap loyalitas konsumen terhadap merek tersebut.

Berdasarkan data yang didapat dari hasil penelitian dengan menggunakan kuesioner kepada 30 orang responden yang dilakukan oleh penulis dapat dilihat bahwa e-sports marketing dan kepuasan pelanggan cukup berpengaruh terhadap loyalitas konsumen akan suatu merek.

Penelitian ini memiliki hipotesis berikut:

H1. Diduga bahwa adanya pengaruh dari e-sports marketing terhadap loyalitas merek Razer Inc.

H2. Diduga bahwa adanya pengaruh dari kepuasan pelanggan terhadap loyalitas merek Razer Inc.

H3. Diduga bahwa adanya pengaruh dari e-sports marketing dan kepuasan pelanggan terhadap loyalitas merek Razer Inc.

Hasil dari penelitian ini adalah sebagai berikut: (1) E-sports marketing berpengaruh cukup signifikan terhadap loyalitas merek Razer Inc. (2) Kepuasan pelanggan berpengaruh signifikan terhadap loyalitas merek Razer Inc. (3) Pemakaian merek Razer Inc oleh pemain profesional dan streamer serta sponsorship terhadap pemain atau tim profesional mempengaruhi loyalitas merek Razer Inc disertai kepuasan pelanggan terhadap produknya. 


\section{BIBLIOGRAFI}

Andayani, Ni Luh Henny. (2014). Manajemen Pemasaran Pariwisata. Yogyakarta: Penebit Graha Ilmu.

Ari Setyaningrum, J. U. (2015). Prinsip-Prinsip Pemasaran. Yogyakarta: Andi.

Fletcher, Alex. (2015). eSports Marketing: The Birth of a Nation. Retrieved from https://esportsobserver.com/esports-marketing-the-birth-of-a-nation

Gawrysiak, Joey, Burton, Rick, Jenny, Seth, \& Williams, Dylan. (2020). Using Esports Efficiently to Enhance and Extend Brand Perceptions-A Literature Review. Physical Culture and Sport. Studies and Research, 86(1), 1-14.

H.B, Duran. (2016). Nielsen: Brand Loyalty Grows With Esports Involvement. Retrieved from https://www.alistdaily.com/digital/nielsen-brand-loyalty-growsesports-involvement/

Hamari, Juho, \& Sjöblom, Max. (2017). What is eSports and why do people watch it? Internet Research.

Kotler, Philip. (n.d.). Philip, and Kevin Lane Keller. 2013. Marketing Management.

Moleong, L. J. (2011). Metode Penelitian Edisi Revisi. Bandung: PT Remaja Rosdakarya.

Pramadita, Indra. (2017). Embedded Graphic Online Service. Syntax Literate; Jurnal Ilmiah Indonesia, 2(1), 14-20.

Priansa, Donni Juni. (2017). Perilaku konsumen dalam persaingan bisnis kontemporer. Bandung: Alfabeta.

Saputro, Danang Adi, Hufron, Muhammad, \& Slamet, Afi Rachmat. (2017). Pengaruh kepuasan pelanggan, kepercayaan pelanggan dan switching barriers terhadap loyalitas pelanggan (studi kasus pada toko Ogan Malang). Jurnal Ilmiah Riset Manajemen, 6(02).

Schiffman, L., Wisenblit, L., . (2015). Consumer Behavior (Edisi Sebe). Pearson Education.

Sugiyono. (2016). Metode Penelitian Kuantitatif, Kualitatif R\&D. Bandung: Alfabrta.

Tjiptono, Fandy. (2014). Pemasaran Jasa-Prinsip, Penerapan, dan Penelitian. Yogyakarta: Andi Offset.

Verma, Deepak. (2018). A Critical Review of Digital Marketing. 8. 321-339. 